\title{
Supervised Optimization of Fuel Ratio in IC Engine Based on Design Baseline Computed Fuel Methodology
}

\author{
Farzin Piltan \\ Industrial Electrical and Electronic Engineering SanatkadeheSabze Pasargad. CO (S.S.P. Co), NO:16, PO.Code 71347- \\ 66773, Fourth floor, Dena Apr, Seven Tir Ave, Shiraz, Iran \\ Email: SSP.ROBOTIC@gmail.com
}

Saeed Zare

Industrial Electrical and Electronic Engineering SanatkadeheSabze Pasargad. CO (S.S.P. Co), NO:16 , PO.Code 7134766773, Fourth floor, Dena Apr, Seven Tir Ave, Shiraz, Iran

Email:SSP.ROBOTIC@yahoo.com

Fatemeh ShahryarZadeh

Industrial Electrical and Electronic Engineering SanatkadeheSabze Pasargad. CO (S.S.P. Co), NO:16 , PO.Code 7134766773, Fourth floor, Dena Apr, Seven Tir Ave, Shiraz, Iran

Email: SSP.ROBOTIC@yahoo.com

Mohammad Mansoorzadeh

Industrial Electrical and Electronic Engineering SanatkadeheSabze Pasargad. CO (S.S.P. Co), NO:16, PO.Code 7134766773, Fourth floor, Dena Apr, Seven Tir Ave, Shiraz, Iran

Email: SSP.ROBOTIC@yahoo.com

\author{
Marzieh kamgari \\ Industrial Electrical and Electronic Engineering SanatkadeheSabze Pasargad. CO (S.S.P. Co), NO:16 , PO.Code 71347- \\ 66773, Fourth floor, Dena Apr, Seven Tir Ave, Shiraz, Iran \\ Email: SSP.ROBOTIC@yahoo.com
}

\begin{abstract}
Internal combustion (IC) engines are optimized to meet exhaust emission requirements with the best fuel economy. Closed loop combustion control is a key technology that is used to optimize the engine combustion process to achieve this goal. In order to conduct research in the area of closed loop combustion control, a control oriented cycle-to-cycle engine model, containing engine combustion information for each individual engine cycle as a function of engine crank angle, is a necessity. In this research, the IC engine is modeled accord ing to fuel ratio, which is represented by the mass of air. In this research, a multi-input-multioutput baseline computed fuel control scheme is used to simultaneously control the mass flow rate of both port fuel injection (PFI) and direct in jection (DI) systems to regulate the fuel ratio of PFI to DI to desired levels. The control target is to maintain the fuel ratio at stoichiometry and the fuel ratio to a desired value between zero and one. The performance of the baseline computed fuel controller is compared with that of a baseline proportional, integral, and derivative (PID) controller.
\end{abstract}

Index Terms - IC engine, fuel ratio, port fuel in jection, direct injection, baseline controller, computed fuel controller.

\section{Introduction}

The internal combustion (IC) engine is designed to produce power from the energy that is contained in its fuel. More specifically, its fuel contains chemical energy and together with air, this mixture is burned to output mechanical power. There are various types of fuels that can be used in IC engines which include petroleum, bio-fuels, and hydrogen. In an internal combustion engine, a piston moves up and down in a cylinder and power is transferred through a connecting rod to a crank shaft. The continual motion of the piston and rotation of the crank shaft as air and fuel enter and exit the cylinder through the intake and exhaust valves is known as an engine cycle. The first and most significant engine among all internal combustion engines is the Otto engine, which was developed by 
Nicolaus A. Otto in 1876 [1-8]. In his engine, Otto created a unique engine cycle that consisted of four piston strokes. These strokes are:

1. Intake stroke

2. Compression stroke

3. Expansion stroke

4. Exhaust stroke

Modeling of an entire IC engine is a very important and complicated process because engines are nonlinear, multi inputs-multi outputs and time variant. One purpose of accurate modeling is to save development costs of real engines and minimizing the risks of damaging an engine when validating controller designs. Nevertheless, developing a small model, for specific controller design purposes, can be done and then validated on a larger, more complicated model. Analytical dynamic nonlinear modeling of internal combustion engine is carried out using elegant EulerLagrange method compromising accuracy and complexity [9-12]. An empirical dynamic nonlinear model of the system is then developed on the bases of neural network and/or neuro-fuzzy. The developed models are verified using several testing approaches such as overlapping, power spectral density and correlation tests [3], [4], [5], [9-16]. The sum of the fuel that is injected into the cylinder by the port fuel injector and the direct fuel injector is the total fuel, $\dot{M}_{F u e l}$. The amount of fuel injected by one injector divided by the sum of the two is the fuel ratio of PFI to DI. The fuel ratio can be used to determine which fuel system should have a larger impact on how much fuel is injected into the cylinder. Since a direct fuel injector has immediate injection of its fuel with significant charge cooling effect, it can have a quicker response to the desired amount of fuel that is needed by an engine. Although a port fuel injector may have a slower response due to its wall-wetting dynamics, the fuel ratio will impact the combustion characteristics of an engine. Fuel ratio also can be used to regulate or control two fuel types. For example, an engine may have the ability to run on gasoline and ethanol. The gasoline could be injected by a port fuel injector, while the ethanol could be injected by a direct injector. Although, implementation of this may require to separate fuel lines and separate fuel tanks, the ratio of gasoline to ethanol, or two other types of fuels, may be of interest to future engine control designers [17-19].

Controller is a device which can sense information from linear or nonlinear system (e.g., IC engine) to improve the systems performance [20-22]. The main targets in designing control systems are stability, good disturbance rejection, and small tracking error[5, 23-40]. Several IC engine are controlled by linear methodologies (e.g., Proportional-Derivative (PD) controller, Proportional- Integral (PI) controller or Proportional- Integral-Derivative (PID) controller), but when IC engine works in various situation and have uncertainty in dynamic models this technique has limitations. Strong mathematical tools used in new control methodologies to design nonlinear robust controller with an acceptable performance (e.g., minimum error, good trajectory, disturbance rejection). Baseline computed fuel controller (BCFC) is an influential nonlinear controller to certain and partly uncertain systems which it is based on feedback linearization and computes the required outputs using the nonlinear feedback control law. When all dynamic and physical parameters are known, BCFC works superbly. There have been several engine controller designs over the past 40 years in which the goal is to improve the efficiency and exhaust emissions of the automotive engine. A key development in the evolution was the introduction of a closed loop fuel injection control algorithm by Rivard in the 1973 [7]. This strategy was followed by an innovative linear quadratic control method in 1980 by Cassidy [8] and an optimal control and Kalman filtering design by Powers [9]. Although the theoretical design of these controllers was valid, at that time it was not realistic to implement such complex designs. Therefore, the production of these designs did not exist and engine designers did adopt the methods [41-47]. Due to the increased production of the microprocessor in the 1990's, it became practical to use these microprocessors in developing more complex control and estimation algorith ms that could potentially be used in production automotive engines. Specific applications of fuel ratio control based on observer measurements in the intake manifold was developed by Benninger in 1991 [10]. Another approach was to base the observer on measurements of exhaust gases measured by the oxygen sensor and on the throttle position, which was researched by Onder [11]. These observer ideas used linear observer theory. Hedrick also used the measurements of the oxygen sensor to develop a nonlinear, sliding mode approach to control the A/F ratio [12]. All of the previous control strategies were applied to engines that used only port fuel injections, where fuel was injected in the intake manifold. The development of these control strategies for direct injection was not practical because the production of direct injection automobiles did not begin until the mid 1990's. Mitsubishi began to investigate combustion control technologies for direct injection engines in 1996 [13]. Furthermore, engines that used both port fuel and direct systems appeared a couple years ago, leading to the interest of developing the corresponding control strategies. Current production A/F ratio controllers use closed loop feedback and feed forward control to achieve the desired stoichiometric mixture. These controllers use measurements from the oxygen sensor to control the desired amount of fuel that should be injected over the next engine cycle and have been able to control the A/F very well.

This paper is organized as follows. In section 2, main subject of dynamic formulation of IC engine is presented. A methodology of proposed baseline computed fuel controller is presented in section 3. In 
section 4, the baseline controller and proposed methodology are compared and discussed. In section 5, the conclusion is presented.

\section{Theory}

Dynamic modeling of IC engine is used to describe the nonlinear behavior of IC engine, design of model based controller such as pure variable structure controller based on nonlinear dynamic equations, and for simulation. The dynamic modeling describes the relationship between fuel to air ratio to PFI and DI and also it can be used to describe the particular dynamic effects (e.g., motor pressure, angular speed, mass of air in cylinder, and the other parameters) to behavior of system[1].

The equation of an IC engine governed by the following equation $[1,4,10,12,15-19]$ :

$$
\begin{aligned}
& {\left[\begin{array}{c}
\mathrm{PFI} \\
\text { DI }
\end{array}\right]=\left[\begin{array}{ll}
\dot{\mathrm{M}}_{\text {air11 }} & \dot{\mathrm{M}}_{\text {air 12 }} \\
\dot{\mathrm{M}}_{\text {air21 }} & \dot{\mathrm{M}}_{\text {air 22 }}
\end{array}\right]\left[\begin{array}{c}
\ddot{F} \\
\ddot{\alpha}_{\mathrm{I}}
\end{array}\right]} \\
& +\left[\begin{array}{l}
\mathbf{P}_{\text {motor }} \\
\mathbf{P}_{\text {motor }}
\end{array}\right]\left[\begin{array}{ll}
\mathbf{F R} & \dot{\alpha}_{\mathrm{I}}
\end{array}\right] \\
& +\left[\begin{array}{ll}
\mathbf{N}_{11} & \mathbf{N}_{12} \\
\mathbf{N}_{21} & \mathbf{N}_{22}
\end{array}\right] \times\left[\begin{array}{c}
\mathbf{F R} \\
\dot{\alpha_{I}}
\end{array}\right]^{2} \\
& +\left[\begin{array}{l}
\mathbf{M}_{\mathrm{a}_{1}} \\
\mathbf{M}_{\mathrm{a}_{2}}
\end{array}\right]
\end{aligned}
$$

Where PFI is port fuel injector, $D I$ is direct injector, $\dot{\mathbf{M}}_{\text {air }}$ is a symmetric and positive define mass of air matrix, $\mathbf{P}_{\text {motor }}$ is the pressure of motor, $N$ is engine angular speed and $\mathbf{M}_{\mathbf{a}}$ is matrix mass of air in cylinder. Fuel ratio and exhaust angle are calculated by [18-19]:

$$
\begin{aligned}
& {\left[\begin{array}{c}
F \ddot{R}_{a} \\
\ddot{\alpha}_{I_{a}}
\end{array}\right]=\left[\begin{array}{ll}
\dot{M}_{\text {air } 11} & \dot{M}_{\text {air } 12} \\
\dot{M}_{\text {air } 21} & \dot{M}_{\text {air } 22}
\end{array}\right]^{-1}\left\{\left[\begin{array}{c}
P F I \\
D I
\end{array}\right]\right.} \\
&-\left\{\left[\begin{array}{c}
P_{\text {motor } 1} \\
P_{\text {motor } 2}
\end{array}\right]\left[\begin{array}{ll}
F R & \dot{\alpha}_{I_{a}}
\end{array}\right]\right. \\
&+\left[\begin{array}{ll}
N_{11} & N_{12} \\
N_{21} & N_{22}
\end{array}\right] \times\left[\begin{array}{c}
F \dot{R}_{a} \\
\alpha_{I_{a}}
\end{array}\right]^{2} \\
&\left.+\left[\begin{array}{c}
M_{a_{1}} \\
M_{a_{2}}
\end{array}\right]\right\}
\end{aligned}
$$

The above target equivalence ratio calculation will be combined with fuel ratio calculation that will be used for controller design purpose.

\section{Methodol ogy}

\subsection{Baseline Methodology}

The design of a baseline methodology to control the fuel ratio was very straight forward. Since there was an output from the fuel ratio model, this means that there would be two inputs into the baseline controller. Similarly, the output of the controller result from the two control inputs of the port fuel injector signal and direct injector signal. In a typical PID method, the controller corrects the error between the desired input value and the measured value. Since the equivalence ratio and fuel ratio are the two measured signals, two controllers were cascaded together to control the PFI and DI inputs. The first was a PID controller that corrected the error between the desired equivalence ratio and the measured equivalence ratio; while the second was only a proportional integral (PI) controller that corrected the fuel ratio error. Figure 1 is shown baseline methodology, applied to IC engine.

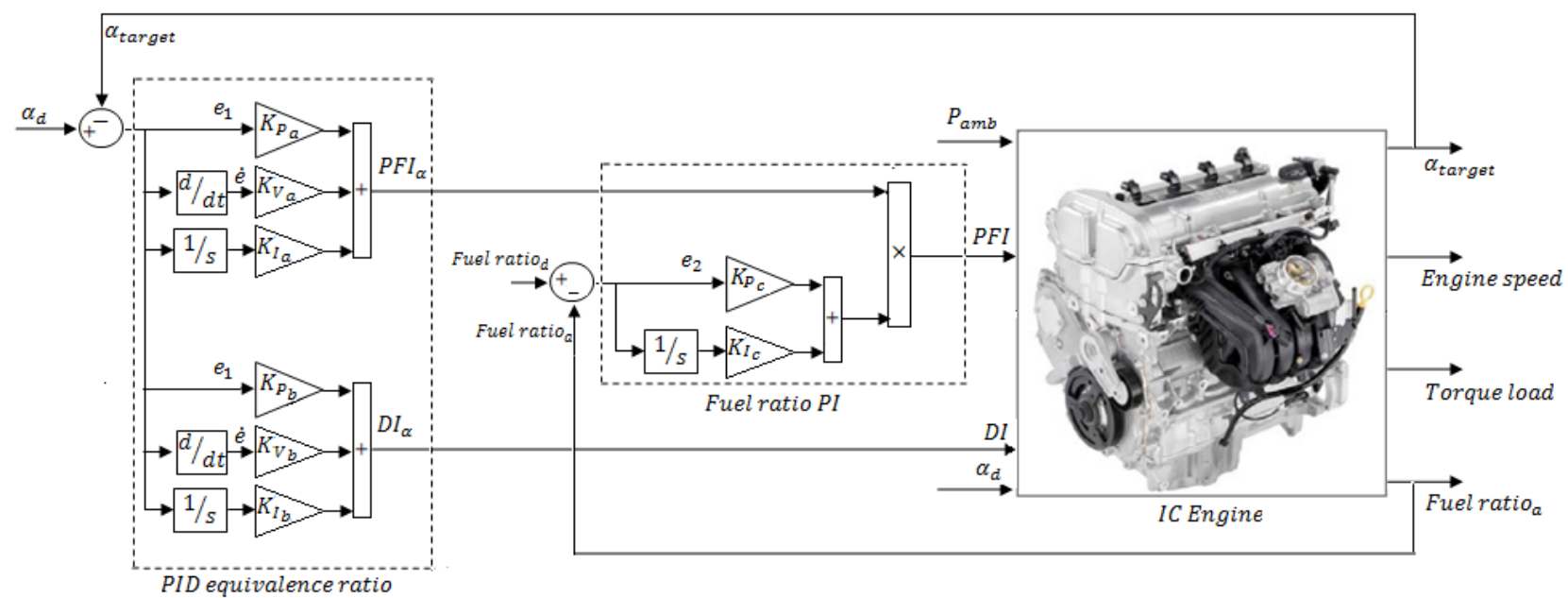

Fig. 1: Block diagram of baseline method

$$
\begin{aligned}
& e_{1}(t)=\alpha_{\text {target }}(t)-\alpha_{d}(t) \\
& e_{2}(t)=\text { Fuel ratio }_{a}(t)-\text { Fuel Ratio }_{d}(t)
\end{aligned}
$$

$$
\begin{gathered}
P F I_{\alpha}=K_{p_{a}} e_{1}+K_{V_{a}} \dot{e}_{1}+K_{I_{a}} \sum e_{1} \\
D I_{\alpha}=K_{p_{b}} e_{1}+K_{V_{b}} \dot{e_{1}}+K_{I_{b}} \sum e_{1}
\end{gathered}
$$




$$
\begin{aligned}
& P F I_{F}=\left(K_{p_{c}} e_{2}+K_{I_{c}} \sum e_{2}\right) \times P F I_{\alpha} \\
& D I_{F}=D I_{\alpha}
\end{aligned}
$$

\subsection{Computed Fuel Methodology}

Computed fuel optimization (CFM) is a powerful nonlinear optimized supervisory method, which it is widely used in control of fuel ratio of IC engine. It is based on feedback linearization and computes the required engine fuels using the nonlinear feedback control law. This controller works very well when all dynamic and physical parameters are known or partly unknown. In practice, most of physical systems (e.g., IC engines) parameters are unknown or time variant, therefore, BCFC used to compensate dynamic equation of IC engine. Research on BCFC is significantly growing on IC engine application. Vivas and Mosquera have proposed a predictive functional controller and compare to computed fuel methodology (CFM) for tracking response in uncertain environment. However both controllers have been used in feedback linearization, but predictive strategy gives better result as a performance. When all dynamic and physical parameters are known, CFM works fantastically. The central idea of CFM is feedback linearization so, originally this algorithm is called computed fuel controller. It has assumed that the desired PFI for the IC

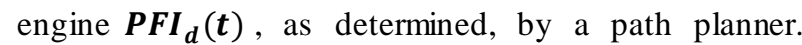
Defines the error as:

If an alternative linear state-space equation in the form $\dot{\boldsymbol{x}}=\boldsymbol{A} \boldsymbol{x}+\boldsymbol{B} \boldsymbol{U}$ can be defined as

$$
\dot{x}=\left[\begin{array}{ll}
\mathbf{0} & I \\
\mathbf{0} & \mathbf{0}
\end{array}\right] x+\left[\begin{array}{l}
\mathbf{0} \\
\boldsymbol{I}
\end{array}\right] \boldsymbol{U}
$$

$$
\text { With } \quad U=\left[\begin{array}{l}
P_{\text {motor }_{1}} \\
P_{\text {motor }_{2}}
\end{array}\right]\left[\begin{array}{ll}
F R & \dot{\alpha}_{I a}
\end{array}\right]+\left[\begin{array}{ll}
N_{11} & N_{12} \\
N_{21} & N_{22}
\end{array}\right] \times
$$
$\left[\begin{array}{c}\boldsymbol{F} \boldsymbol{R}_{\boldsymbol{a}} \\ \boldsymbol{\alpha}_{\boldsymbol{I}_{\boldsymbol{a}}}\end{array}\right]^{\mathbf{2}}+\left[\begin{array}{c}\boldsymbol{M}_{\boldsymbol{a}_{1}} \\ \boldsymbol{M}_{\boldsymbol{a}_{2}}\end{array}\right]$ and this is known as the Brunousky canonical form. By (8) and (9) the Brunousky canonical form can be written in terms of the state $\boldsymbol{x}=\left[\boldsymbol{e}^{T} \dot{e}^{T}\right]^{T}$ as [1]:

$$
\frac{d}{d t}\left[\begin{array}{l}
e \\
\dot{e}
\end{array}\right]=\left[\begin{array}{ll}
0 & I \\
0 & 0
\end{array}\right] \cdot\left[\begin{array}{l}
e \\
\dot{e}
\end{array}\right]+\left[\begin{array}{l}
0 \\
I
\end{array}\right] U
$$

This is a nonlinear feedback control law that guarantees tracking of IC engine trajectory. Selecting proportional-plus-derivative (PD) feedback for $\mathrm{U}(\mathrm{t})$ results in the PD-FELC ;

$$
\begin{aligned}
& P F I=P \ddot{F} I_{d}\left\{\left(F \ddot{R}_{d}+K_{p} e+K_{v} \dot{e}\right) \times\right. \\
& \left.\left[\begin{array}{ll}
\dot{\mathbf{M}}_{\text {air } 11} & \dot{\mathbf{M}}_{\text {air } 12} \\
\dot{\mathbf{M}}_{\text {air } 21} & \dot{\mathbf{M}}_{\text {air 22 }}
\end{array}\right]\right\}+\left[\begin{array}{l}
P_{\text {motor }_{1}} \\
P_{\text {motor }_{2}}
\end{array}\right]\left[\begin{array}{ll}
F_{R R} & \dot{\alpha}_{I_{a}}
\end{array}\right]+ \\
& {\left[\begin{array}{ll}
N_{11} & N_{12} \\
N_{21} & N_{22}
\end{array}\right] \times\left[\begin{array}{c}
F \dot{R}_{a} \\
{\dot{I_{I}}}_{a}
\end{array}\right]^{2}+\left[\begin{array}{c}
M_{a_{1}} \\
M_{a_{2}}
\end{array}\right]}
\end{aligned}
$$

According to the linear system theory, convergence of the tracking error to zero is guaranteed. Where $\boldsymbol{K}_{\boldsymbol{p}}$ and $\boldsymbol{K}_{\boldsymbol{v}}$ are the controller gains. Based on Figure 2, this system has two feedback loops, namely, inner loop and outer loop, which an inner loop is a compensate loop and an outer loop is a tracking error loop.

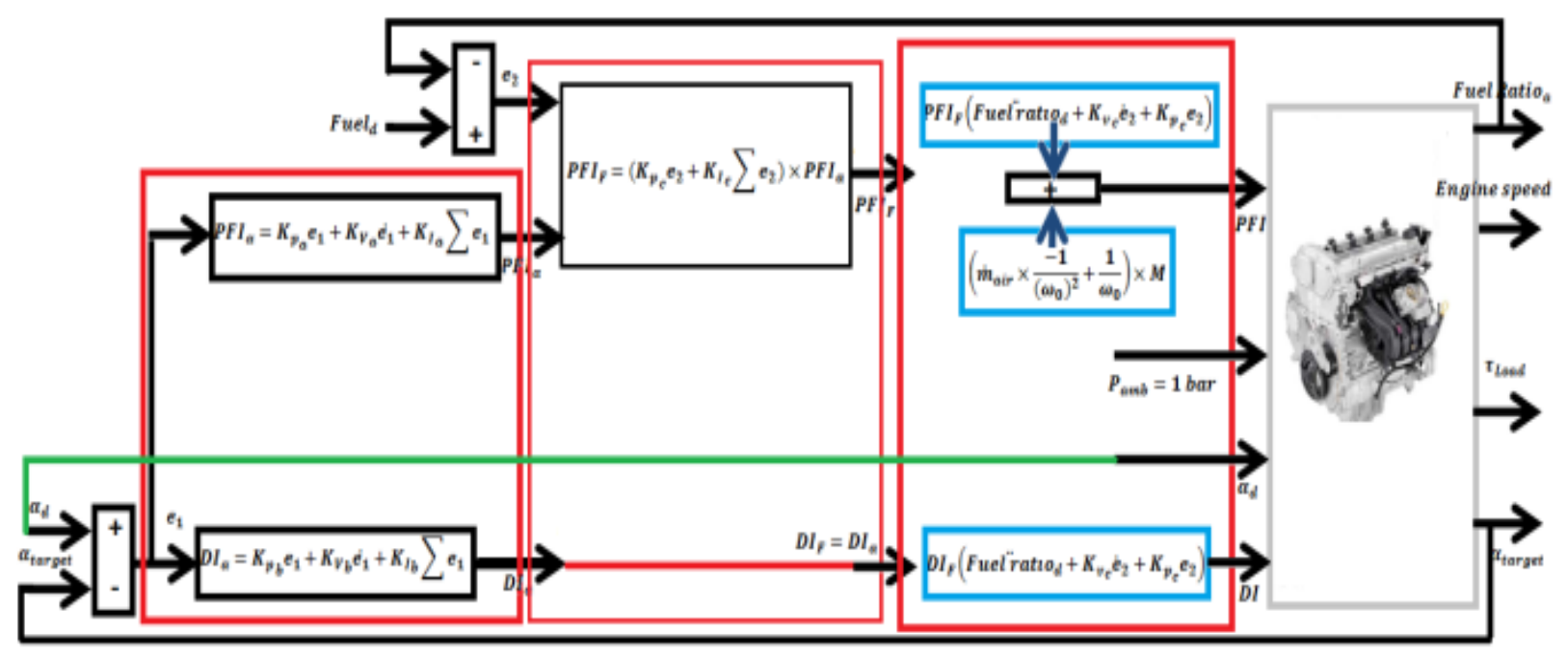

Fig. 2: Block diagram of BCFC

\section{Results and Discussion}

This part is focused on compare between baseline controller $(\mathrm{BC})$ and baseline computed fuel controller (BCFC). These controllers were tested by step fuel ratio and equivalence ratio. The simu lation was implemented in MATLAB/SIMULINK environment. Close loop response of fuel ratio and close loop response of equivalence ratio without any disturbance and in presence of disturbance are compared in these methodologies.

Close loop response of fuel ratio without any disturbance: Figure 3 is shown the control of fuel ratio based on two methods: baseline computed fuel controller and baseline controller. 


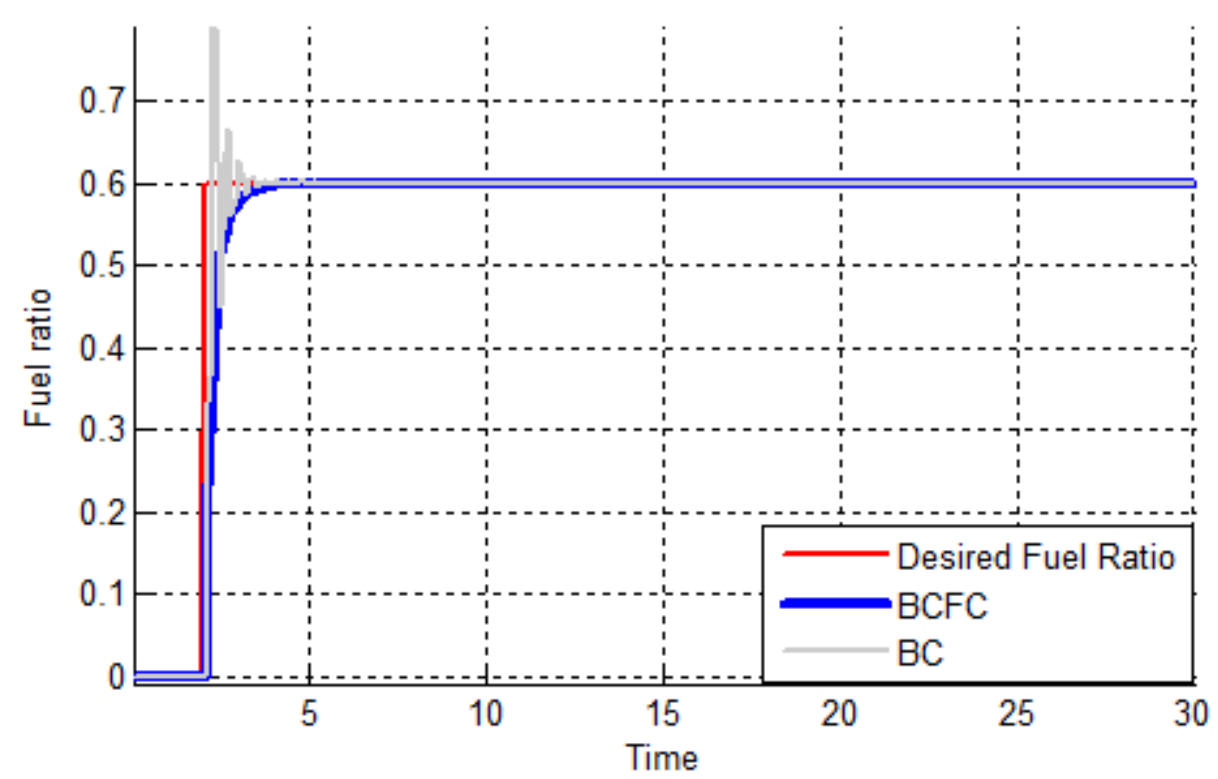

Fig. 3: Baseline computed fuel controller Vs. Baseline controller for fuel ratio performance without disturbance

Based on Figure 3; by comparing fuel ratio response without disturbance in BC and BCFC, BCFC's overshoot about $\mathbf{( 0 . 9 4 \% )}$ ) is lower than BC's (6.44\%). $\mathrm{BC}$ 's rise time (0.403) is lower than BCFC's (0.483).

Close loop response of fuel ratio in presence of torque load disturbance: Figure 4 shows the power disturbance elimination in $\mathrm{BCFC}$ and $\mathrm{BC}$ with torque load disturbance for fuel ratio. The disturbance rejection is used to test the robustness comparisons of these two controllers for fuel ratio. It found fairly fluctuations in fuel ratio responses.

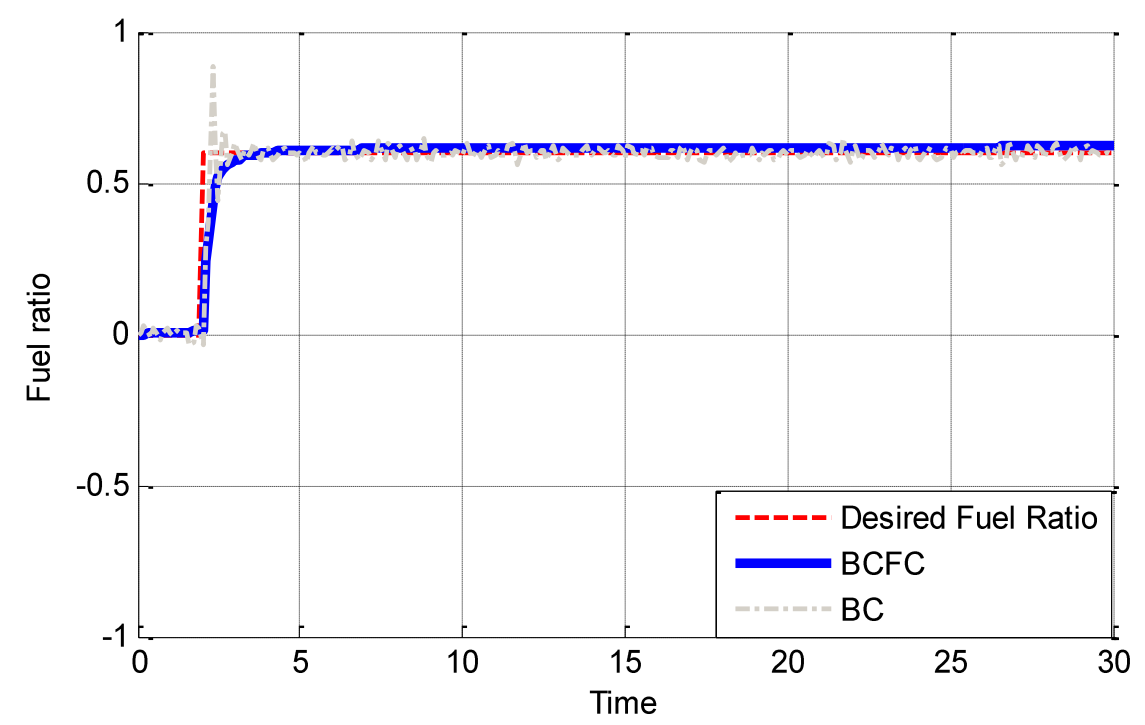

Fig. 4: Baseline computed fuel controller Vs. Baseline controller for fuel ratio performance with torque load dist urbance

Based on Figure 4; by comparing fuel ratio response in presence of torque load disturbance in $\mathrm{BC}$ and $\mathrm{BCFC}$, BCFC's overs hoot about ( $0 \%)$ is lower than BC's (5\%). Based on Figure 4, BC has moderately oscillation in fuel ratio response with regard to torque load disturbance but BCFC has stability in trajectory responses. Based on Figure 4 in presence of torque load unstructured disturbance, BCFC's is more robust than
$\mathrm{BC}$, because $\mathrm{BCFC}$ is a nonlinear linear controller and it has more than $\mathrm{BC}$ 's tuning parameters.

Close loop response of throttle equi valence ratio without disturbance: Figure 5 is shown the control of throttle equivalence ratio $\left(\alpha_{\text {target }}\right)$ based on two methods: baseline computed fuel controller and baseline controller. 


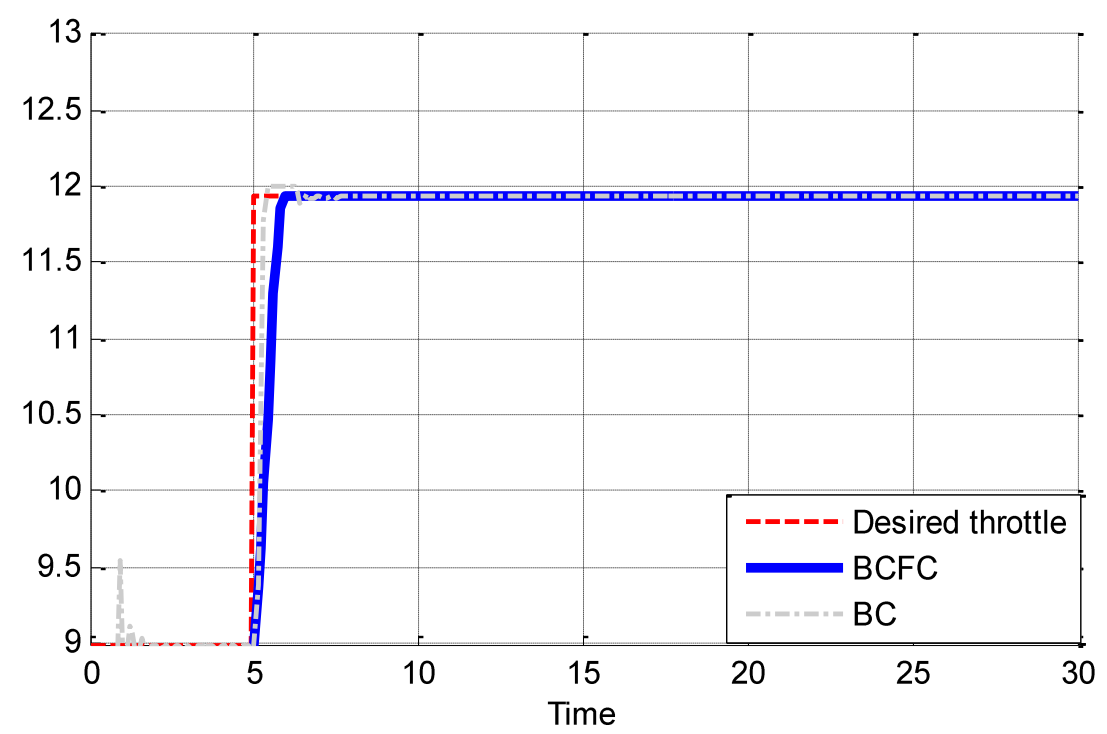

Fig. 5: Baseline computed fuel controller Vs. Baseline controller for throttle equivalence ratio performance without disturbance

Based on Figure 5; by comparing throttle response without disturbance in $\mathrm{BC}$ and BCFC, BCFC's overshoot about $\mathbf{( 0 . 2 2 \%})$ is lower than BC's $\mathbf{( 2 . 1 \% )}$. BC's rise time (0.403) is lower than BCFC's (0.483).

Close loop res ponse of throttle equi valence $r$ atio in presence of torque load disturbance: Figure 6 shows the power disturbance elimination in $\mathrm{BCFC}$ and $\mathrm{BC}$ with torque load disturbance for throttle equivalence ratio. The disturbance rejection is used to test the robustness comparisons of these two controllers for throttle equivalence. It found fairly fluctuations in BC throttle equivalence responses.

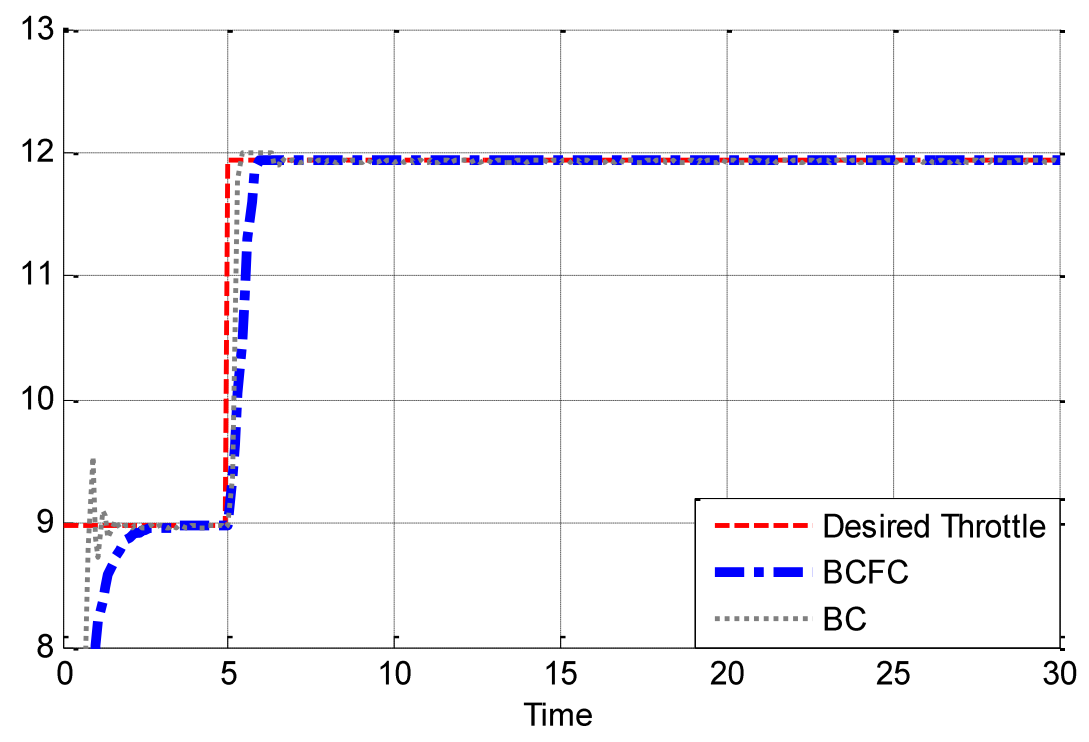

Fig. 6: Baseline computed fuel controller Vs. Baseline controller for throttle equivalenceratio performance in presence of torque load disturbance

Based on Figure 6; by comparing throttle equivalence response in presence of torque load disturbance in $\mathrm{BC}$ and $\mathrm{BCFC}, \mathrm{BCFC}$ 's overs hoot about $(0 \%)$ is lower than BC's (3.2\%). Based on Figure 6, BC has moderately oscillation in throttle response with regard to torque load disturbance but BCFC has stability in throttle responses. Based on Figure 6 in presence of torque load unstructured disturbance, BCFC's is more robust than $\mathrm{BC}$, because $\mathrm{BCFC}$ is a nonlinear linear controller and it has more than BC's tuning parameters.

\section{Conclusion}

In this research, a multi-input-multi-output baseline computed fuel control scheme is used to simultaneously control the mass flow rate of both port fuel injection (PFI) and direct injection (DI) systems to regulate the fuel ratio of PFI to DI to desired levels. The control target is to maintain the fuel ratio at stoichiometry and the fuel ratio to a desired value between zero and one (the best number is 0.6 ). This controller has two inputs, 
$e_{1}$ and $e_{2}$, and two outputs, PFI and DI. This methodology is useful to control, adjust fuel ratio control, engine speed and equivalence ratio. This is primarily due to the fact that $\mathrm{BC}$ controller is widely used in automotive applications and can be easily implemented. Likewise, the BCFC design was also an excellent MIMO controller. The ability to use BCFC theory on a MIMO case was significant. This supervisory methodology has acceptable performance in presence of uncertainty (e.g., overshoot $=0 \%$, rise time $=0.483$ second, steady state error $=1 \mathrm{e}-9$ and $\mathrm{RMS}$ error=1.8e-12).

\section{Acknowledgment}

The authors would like to thank the anonymous reviewers for their careful reading of this paper and for their helpful comments. This work was supported by the SSP Research and Development Corporation Program of Iran undergrant no. 2012-Persian Gulf-2B.

\section{References}

[1] Heywood, J., "Internal Combustion Engine Fundamentals”, McGraw-Hill, New York, 1988.

[2] Ferguson, C., "Internal Combustion Engines: Applied Thermosciences", John Wiley \& Sons, Inc., New York, 2001.

[3] Guzzella, L., "Introduction to Modeling and Control of Internal Co mbustion Engine Systems" Springer, New York, 2004.

[4] Ramos, J., "Internal Combustion Engine Modeling”, Hemisphere Publishing corporation, New York, 1989.

[5] Blair, G., "Design and Simulation of Four Stroke Engines", Society of Automotive Engineers, Warrendale, $\mathrm{Pa}, 1999$.

[6] G. Zhu, et al, "Closed-Loop Ignition Timing Control for SI Engines Using Ionization Current Feedback," IEEE Trans on Control Systems, pp. 416-427, May 2007.

[7] I. Haskara, et al, "On Combustion Invariants For MBT Timing Estimation and Control," in ASME Internal Combustion Engine Division, 2004.

[8] Farzin Piltan, S. Siamak, M. A Bairami, I. Nazari,” Gradient Descent Optimal Chattering Free Sliding Mode Fuzzy Control Design: Lyapunov Approach," International Journal of Advance Science and Technology, 45: 73-90, 2012.

[9] Farzin Piltan, M. A. Bairami, F. Aghayari, S. Allahdadi, "Design Adaptive Artificial Inverse Dynamic Controller: Design Sliding Mode Fuzzy Adaptive New Inverse Dynamic Fuzzy Controller," International Journal of Robotic and Automation, 3 (1): 13-26, 2012.
[10] Dawson, J., “An experimental and Computational Study of Internal Combustion Engine Modeling for Controls Oriented Research" Ph.D. Dissertation, The Ohio State University, 2005.

[11] Lee, B., "Methodology for the Static and Dynamic Model Based Engine Calibration and Optimization" Ph.D. Dissertation, The Ohio State University, 2005.

[12] Soteris A. Kalogirou," Artificial intelligence for the modeling and control of combustion processes: a review", Progress in Energy and Combustion Science, science direct, 2003.

[13] J. G. Rivard, "Closed-loop Electronic Fuel Injection Control of the IC Engine," in Society of Automotive Engineers, 1973.

[14] J. F. Cassidy, et al, "On the Design of Electronic Automotive Engine Controls using linear Quadratic Control Theory," IEEE Trans on Control Systems, vol. AC-25, October 1980.

[15] W. E. Powers, "Applications of Optimal Control and Kalman Filtering to Automotive Systems," International Journal of Vehicle Design, vol. Applications of Control Theory in the Automotive Industry, 1983.

[16] N. F. Benninger, et al, "Requirements and Perfo mance of Engine Management Systems under Transient Conditions," in Society of Automotive Engineers, 1991.

[17] C. H. Onder, et al, "Model-Based Multivariable Speed and Air-to-Fuel Ratio Control of an SI Engine," in Society of Automotive Engineers, 1993.

[18] S. B. Cho, et al, "An Observer-based Controller Design Method for Automotive Fuel-Injection Systems," in A merican Controls Conference, 1993, pp. 2567-2571.

[19] T. Kume, et al, "Combustion Technologies for Direct Injection SI Engine," in Society of Automotive Engineers, 1996.

[20] Farzin Piltan , N. Sulaiman, Zahra Tajpaykar, Payman Ferdosali, Mehdi Rashidi, "Design Artificial Nonlinear Robust Controller Based on CTLC and FSMC with Tunable Gain," International Journal of Robotic and Automation, 2 (3): 205-220, 2011.

[21] Farzin Piltan, A. R. Salehi and Nasri B Sulaiman.," Design artificial robust control of second order system based on adaptive fuzzy gain scheduling," world applied science journal (WASJ), 13 (5): 1085-1092, 2011.

[22] Farzin Piltan, N. Sulaiman, Atefeh Gavahian, Samira Soltani, Samaneh Roosta, "Design Mathematical Tunable Gain PID-Like Sliding Mode Fuzzy Controller with Minimum Rule Base," 
International Journal of Robotic and Automation, 2 (3): 146-156, 2011.

[23] Farzin Piltan, A. Zare, Nasri B. Sulaiman, M. H. Marhaban and R. Ramli, , "A Model Free Robust Sliding Surface Slope Adjustment in Sliding Mode Control for Robot Manipulator," World Applied Science Journal, 12 (12): 2330-2336, 2011.

[24] Farzin Piltan, A. H. Aryanfar, Nasri B. Sulaiman, M. H. Marhaban and R. Ramli "Design Adaptive Fuzzy Robust Controllers for Robot Manipulator," World Applied Science Journal, 12 (12): 2317 2329, 2011.

[25] Farzin Piltan, N. Sulaiman , Arash Zargari, Mohammad Keshavarz, Ali Badri, "Design PIDLike Fuzzy Controller With Minimum Rule Base and Mathematical Proposed On-line Tunable Gain: Applied to Robot Manipulator," International Journal of Artificial intelligence and expert system, 2 (4):184-195, 2011.

[26] Farzin Piltan, Nasri Sulaiman, M. H. Marhaban and R. Ramli, "Design On-Line Tunable Gain Artificial Nonlinear Controller," Journal of Advances In Computer Research, 2 (4): 75-83, 2011.

[27] Farzin Piltan, N. Su laiman, Payman Ferdosali, Iraj Assadi Talooki, “ Design Model Free Fuzzy Sliding Mode Control: Applied to Internal Combustion Engine," International Journal of Engineering, 5 (4):302-312, 2011.

[28] Farzin Piltan, N. Sulaiman, Samaneh Roosta, M.H. Marhaban, R. Ramli, "Design a New Sliding Mode Adaptive Hybrid Fuzzy Controller," Journal of Advanced Science \& Engineering Research , 1 (1): 115-123, 2011.

[29] Farzin Piltan, Atefe Gavahian, N. Sulaiman, M.H. Marhaban, R. Ramli, "Novel Sliding Mode Controller for robot manipulator using FPGA," Journal of Advanced Science \& Engineering Research, 1 (1): 1-22, 2011.

[30] Farzin Piltan, N. Sulaiman, A. Jalali \& F. Danesh Narouei, "Design of Model Free Adaptive Fuzzy Computed Torque Controller: Applied to Nonlinear Second Order System," International Journal of Robotics and Automation, 2 (4):232-244, 2011.

[31] Farzin Piltan, N. Sulaiman, Iraj Asadi Talooki, Payman Ferdosali, "Control of IC Engine: Design a Novel MIMO Fuzzy Backstepping Adaptive Based Fuzzy Estimator Variable Structure Control ," International Journal of Robotics and Automation, 2 (5):360-380, 2011.

[32] Farzin Piltan, N. Sulaiman, Payman Ferdosali, Mehdi Rashidi, Zahra Tajpeikar, "Adaptive MIMO Fuzzy Compensate Fuzzy Sliding Mode Algorith m: Applied to Second Order Nonlinear System,"
International Journal of Engineering, 5 (5): 380 398, 2011.

[33] Farzin Piltan, N. Sulaiman, Hajar Nasiri, Sadeq Allahdadi, Mohammad A. Bairami, "Novel Robot Manipulator Adaptive Artificial Control: Design a Novel SISO Adaptive Fuzzy Sliding Algorithm Inverse Dynamic Like Method," International Journal of Engineering, 5 (5): 399-418, 2011.

[34] Farzin Piltan, N. Sulaiman, Sadeq Allahdadi, Mohammadali Dialame, Abbas Zare, "Position Control of Robot Manipulator: Design a Novel SISO Adaptive Sliding Mode Fuzzy PD Fuzzy Sliding Mode Control," International Journal of Artificial intelligence and Expert System, 2 (5):208-228, 2011.

[35] Farzin Piltan, SH. Tayebi HAGHIGHI, N. Sulaiman, Iman Nazari, Sobhan Siamak, "Artificial Control of PUMA Robot Manipulator: A-Review of Fuzzy Inference Engine And Application to Classical Controller ," International Journal of Robotics and Automation, 2 (5):401 -425, 2011.

[36] Farzin Piltan, N. Sulaiman, Abbas Zare, Sadeq Allahdadi, Mohammadali Dialame, "Design Adaptive Fuzzy Inference Sliding Mode Algorith m: Applied to Robot Arm," International Journal of Robotics and Automation , 2 (5): 283-297, 2011.

[37] Farzin Piltan, Amin Jalali, N. Sulaiman, Atefeh Gavahian, Sobhan Siamak, "Novel Artificial Control of Nonlinear Uncertain System: Design a Novel Modified PSO SISO Lyapunov Based Fuzzy Sliding Mode Algorithm ," International Journal of Robotics and Automation, 2 (5): 298316, 2011.

[38] Farzin Piltan, N. Sulaiman, Amin Jalali, Koorosh Aslansefat, "Evolutionary Design of Mathematical tunable FPGA Based MIMO Fuzzy Estimator Sliding Mode Based Lyapunov Algorithm: Applied to Robot Manipulator," International Journal of Robotics and Automation, 2 (5):317-343, 2011.

[39] Farzin Piltan, N. Sulaiman, Samaneh Roosta, Atefeh Gavahian, Samira Soltani, "Evolutionary Design of Backstepping Artificial Sliding Mode Based Position Algorithm: Applied to Robot Manipulator,' International Journal of Engineering, 5 (5):419-434, 2011.

[40] Farzin Piltan, N. Sulaiman, S.Soltani, M. H. Marhaban \& R. Ramli, "An Adaptive sliding surface slope adjustment in PD Sliding Mode Fuzzy Control for Robot Manipulator," International Journal of Control and Automation , 4 (3): 65-76, 2011.

[41] Farzin Piltan, N. Sulaiman, Mehdi Rashidi, Zahra Tajpaikar, Payman Ferdosali, "Design and Implementation of Sliding Mode Algorithm: 
Applied to Robot Manipulator-A Review ," International Journal of Robotics and Automation, 2 (5):265-282, 2011.

[42] Farzin Piltan, N. Sulaiman, Amin Jalali, Sobhan Siamak, and Iman Nazari, "Control of Robot Manipulator: Design a Novel Tuning MIMO Fuzzy Backstepping Adaptive Based Fuzzy Estimator Variable Structure Control ," International Journal of Control and Automation, 4 (4):91-110, 2011.

[43] Farzin Piltan, N. Sulaiman, Atefeh Gavahian, Samaneh Roosta, Samira Soltani, "On line Tuning Premise and Consequence FIS: Design Fuzzy Adaptive Fuzzy Sliding Mode Controller Based on Lyaponuv Theory," International Journal of Robotics and Automation, 2 (5):381-400, 2011.

[44] Farzin Piltan, N. Sulaiman, Samaneh Roosta, Atefeh Gavahian, Samira Soltani, "Artificial Chattering Free on-line Fuzzy Sliding Mode Algorithm for Uncertain System: Applied in Robot Manipulator," International Journal of Engineering, 5 (5):360-379, 2011.

[45] Farzin Piltan, N. Sulaiman and I.AsadiTalooki, "Evolutionary Design on-line Sliding Fuzzy Gain Scheduling Sliding Mode Algorithm: Applied to Internal Combustion Engine," International Journal of Engineering Science and Technology, 3 (10):7301-7308, 2011.

[46] Farzin Piltan, Nasri B Su laiman, Iraj Asadi Talooki and Payman Ferdosali.," Designing On-Line Tunable Gain Fuzzy Sliding Mode Controller Using Sliding Mode Fuzzy Algorithm: Applied to Internal Combustion Engine," world applied science journal (WASJ), 15 (3): 422-428, 2011.

[47] Farzin Piltan, N. Sulaiman, M. H. Marhaban, Adel Nowzary, Mostafa Tohidian," "Design of FPGA based sliding mode controller for robot manipulator," International Journal of Robotic and Automation, 2 (3): 183-204, 2011.

[48] Farzin Piltan, S. Allahdadi, M. A. Bairami, H. Nasiri, "Design Auto Adjust Sliding Surface Slope: Applied to Robot Manipulator," International Journal of Robotic and Automation, 3 (1): 27-44, 2012.

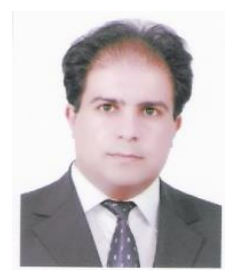

Farzin Piltan was born on 1975, Shiraz, Iran. In 2004 he is jointed the research and development company, SSP Co, Shiraz, Iran. In addition to 7 textbooks, Farzin Piltan is the main author of more than 50 scientific papers in refereed journals. He is editorial board of international journal of control and automation (IJCA), editorial board of International Journal of Intelligent System and Applications (IJISA), editorial board of IAES international journal of robotics and automation, editorial board of International Journal of Reconfigurable and Embedded Systems and reviewer of (CSC) international journal of robotics and automation. His main areas of research interests are nonlinear control, artificial control system and applied to FPGA, robotics and artificial nonlinear control and IC engine modelling and control.

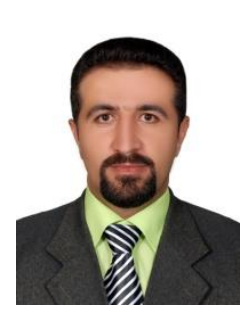

Saeed Zare is an industrial management researcher of research and development company SSP. Co. $\mathrm{He}$ is now pursuing his Master in industrial management. $\mathrm{He}$ is an expert Industrial and Quality Management in this company. His research activities deal with the IC engine control, artificial intelligence and supply chain management.

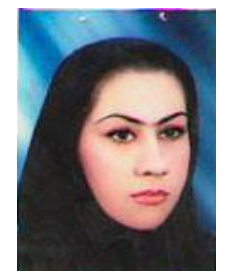

Fatemeh Shahryarzadeh is an electrical and electronic researcher of research and development company SSP. Co. She is an expert electronic and computer engineer in this company. Her research activities deal with the IC engine control, artificial intelligence and expert system.

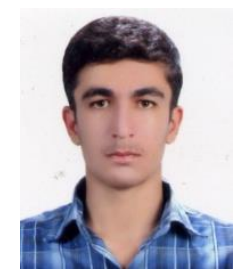

Mohammad Mansoorzadeh is an electrical and electronic researcher of research and development company SSP. Co. He is an expert electronic and computer engineer in this company. His research activities deal with the IC engine control, artificial intelligence and expert system.

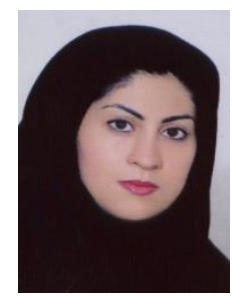

Marzieh Kamgari is an industrial management researcher of research and development company SSP. Co. She is now pursuing her Master in economic. She is an expert Industrial and Quality Management in this company. Her research activities deal with the IC engine control, artificial intelligence and expert system.

How to cite this paper: Farzin Piltan, Saeed Zare, Fatemeh ShahryarZadeh, Mohammad Mansoorzadeh, Marzieh kamgari,"Supervised Optimization of Fuel Ratio in IC Engine Based on Design Baseline Computed Fuel Methodology", International Journal of Information Technology and Computer Science(IJITCS), vol.5, no.4, pp.76-84, 2013.DOI: 10.5815/ijitcs.2013.04.09 